\title{
Green structure in Romania: the true story
}

\author{
O. Luca, F. Petrescu, C. Iacoboaea, F. Gaman, M. Aldea \\ $\&$ M. Sercaianu \\ Department of Urban Engineering and Regional Development, \\ Technical University of Civil Engineering, Romania
}

\begin{abstract}
The European legal framework as well as the current legislation in Romania states that the amount of green space per inhabitant in cities must increase, with specific targets for 2010 and 2013. However, these goals were not met in Romania, and the current development is a slight decrease. At the same time the green structure term is not yet introduced in the planning and strategic documents of the cities. There is no methodological framework in designing and implementing actions and measures in the green structure of the urban areas. The measure "green cadastre" used in Romania by some cities is not a decision making tool in urban development, and do not provide inputs for proactive measures in both conservation and development of the green areas. The paper aims to evaluate the gaps between the designed and existing situation in Romania's cities (with 2 case study presentations) in relation with green areas, the introduction of urban green structure terminology in planning and strategic documents of the cities and the need for a sustainable management of green structure in Romania.
\end{abstract}

Keywords: green structure, green spaces, climate change, sustainability, planning.

\section{Introduction}

The urban green structure is the spatial arrangement of different kinds of vegetation in an urban landscape. The urban green structure is under constant pressure due to urban development; centrally located space for new buildings, roads, car parking, etc. is scarce. 
However, urban areas need vegetation for a number of reasons: conversion of carbon dioxide to oxygen, noise reduction, absorption of water after rainfall, recreation, preservation of biodiversity, and aesthetical value.

Green structure, "considered as the network of green spaces in which and through which natural functions and processes are sustained" (EC 2013-g2) is part of green infrastructure as mentioned in recent EU documents EC (2013-g1), EC (2013-g2), EC (2013-g3), EC (2013-g4), EC (2012-g5), EC (2011-g6), EEA (2011-g7).

Green structure links town and country-side. In a spatial perspective, green structure is more than the sum of green spaces. Speaking of green structure implies drawing attention to the spatial network that links open spaces, public and private gardens, public parks, sports fields, allotment gardens and recreation grounds within the city to the networks of woodlands and river floodplains in the surrounding countryside. Thus green structure highlights the role of greenways for walkers and cyclists and stresses the importance of ecological corridors for wildlife.

The European legal framework as well as the current legislation in Romania recommends that the amount of green space per inhabitant in cities must increase, with specific targets for 2010 and 2013. However, as is demonstrated in the following paragraphs, these goals were not met, and the current development is a slight decrease.

The need for a sustainable management of green structure in Romania is recognized in several programmatic documents and legal provisions [1], though the term green structure is not explicitly mentioned. The green spaces inventory is the reference for further development of the urban planning activities that should take into account the green structure concept.

At the same time there are several Romanian programmatic documents that clearly define "green" objectives that cannot be fulfilled without a sustainable management of the green structure $[2,3]$.

\section{Climate change and green structure}

According to IPCC [4] climate change refers to "a change in the state of the climate that can be identified by changes in the mean and/or the variability of its properties, and that persists for an extended period, typically decades or longer". Climate is affected by human factors (such as changes in land cover and emissions of certain pollutants), natural factors (such as solar radiation and volcanic eruptions), and its own internal dynamics. Some case studies in Europe [5] highlighted that green infrastructure will play an important role in climate change mitigation (carbon storage, fossil fuel substitution, material substitution, reducing the need to travel by car) and adaptation (managing high temperatures, managing water supply, reducing soil erosion, managing visitor pressure etc.). In order to mitigate climate change effects, urban climate studies are the basis for transferring the results of complex meteorological measurements and data into information required and used by local and regional planning authorities. The main meteorological issues are addressed both via direct 
measurements by Parlow [6] and via remote sensing data processing [7-9]. Such studies were already conducted in many cities, all over the world but a lot of work is still needed in order to devise the optimal mitigation strategies. Such a study is the Urban Climate Study of Bucharest, Romania (UCS 2013) [10] developed by the scientific research project number IZERZ0_142160 within the Romanian-Swiss Research Programme 2011-2016 (RSRP 2011). One of the main objectives of the project is to implement modern urban climate strategies in Romania and to analyze in detail and improve the urban climate situation of Bucharest as far as urban heat island, air pollution, heat stress and human comfort is concerned.

Based on the remote sensing techniques there are certain possibilities to assess the quality of the vegetation state at certain periods of time. In the following paragraph there is an example of how this procedure could be applied. Within the "Urban Climate Study of Bucharest/Romania" project we started to process open data satellite imagery such as the well-known Landsat data provided by the USGS. The search criterion in the Landsat archive was first of all to benefit from the long time series of records and to use the same sensor. This criteria was abided by the TM sensor imagery of the Landsat 5 mission so two images were chosen that were recorded as far as possible in time, one after the transition to the market oriented economy and the other as close as possible to the present time. Another criterion was that the images to be recorded on the same date or close enough and in a season propitious for vegetation cover. The NDVI index was used to estimate the vegetation cover. The NDVI is a vegetation density measure based on the mentioned above satellite data and according to Ghorbani et al. [11] is described by eqn (1):

$$
\mathrm{NDVI}=\left[\left(\rho_{\mathrm{NIR}}-\rho_{\mathrm{RED}}\right) /\left(\rho_{\mathrm{NIR}}+\rho_{\mathrm{RED}}\right)\right]
$$

where $\rho$ is the reflectance value in the RED and NIR bands.

The NDVI pixel value is large if the vegetation is dense and small if there is no vegetation, according to Qi et al. [12] and the NDVI equation produces values in the range of -1.0 to 1.0. Based on the NDVI interpretation and on the general case in the scientific literature like the findings of Agone and Bhamare [13], Ghorbani et al. [11] the NDVI value for the two images of Bucharest varied between 0.27 and 0.8 for dense vegetation, and 0.1 and 0.2 for bare soil. Very low negative values for water bodies were also observed. The figures presented below are preliminary results of the "Urban Climate Study of Bucharest/Romania" project, results that need to be further validated.

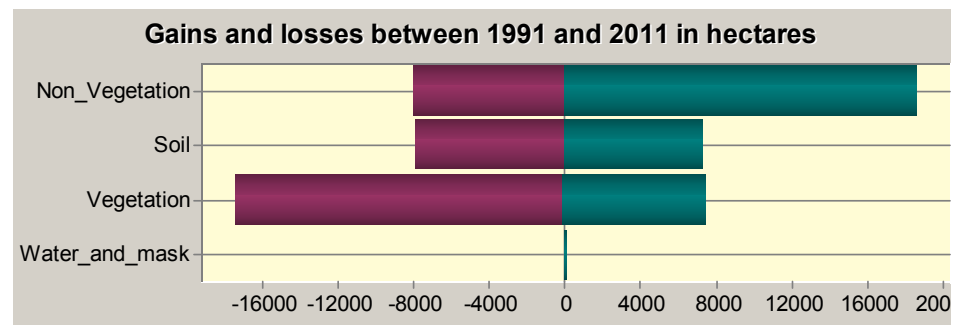

Figure 1: Gains and losses between 1991 and 2011 in the land cover classes. 


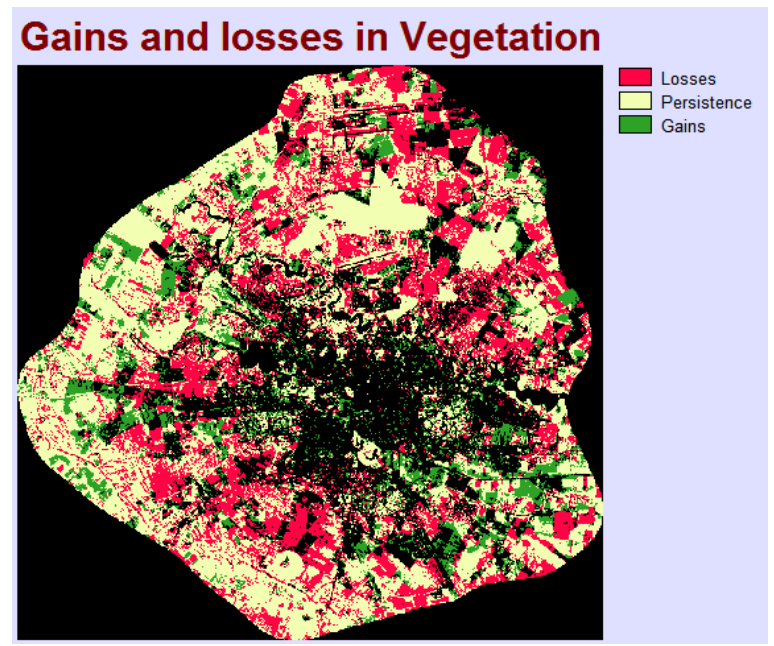

Figure 2: Change detection in vegetation between 1991 and 2011.

\section{Green structures situation in Romania}

In Romania, green structure is not yet a familiar term used in urban planning and strategic planning documentation. The most well-known aspect related to green spaces (areas) in Romania is related to the so called "Green Cadastre", namely The Local Inventory of Green Spaces, established through a series of legal provisions, namely:

- Ordinance nr. 114/2007, art II

- Order 1549/2008 related to Technical Rules for Local Green Spaces Register

- Law nr.313/2009 for amending and supplementing the Law nr. 24/2007 related to the regulation and management of urban green spaces

- Order 1466/2010MDRT amending the Order of Ministry of Development, Public Works and Housing no. 1549/2008

Green areas are defined in the legislation mentioned above as the land inside the settlements which are:

a) public green space with unlimited access: parks, gardens, squares, planted strips;

b) public green spaces such as:

1. botanical and zoological gardens, museums outdoor parks exhibition, environmental and recreational areas for the animals trained in circuses;

2. green areas related to public facilities: nurseries, kindergartens, schools, units, health or welfare institutions, religious buildings, cemeteries;

3. sports grounds and parks for sport performance.

c) green spaces for recreation: recreation, leisure poles, and sports complexes;

d) green spaces to protect lakes and streams;

e) protection corridors related to technical infrastructure;

f) recreational forests. 
First of all, according to the above legislation, all municipalities in Romania must comply with the requirement of providing public urban green space of $20 \mathrm{sq}$ /inhabitant before 31 December 2010, and minimum $26 \mathrm{sq} \mathrm{m} /$ inhabitant, before December 31, 2013. There are also technical rules for the development of the Local Green Space Register, which must be updated every 2 years. However, the Ministry which initiated the Local Green Space Inventory did not establish a centralized public list with the cities which adopted the Register. At the same time, cities which adopted the first version of the Green Spaces Inventory (in 2010 or 2011), did not update it, even though the legislation specifies a 2 year period for updating. A general problem seems to be that the cities find it too time consuming to establish and/or maintain their local green space inventory, and that they do not see benefits from maintaining it that may justify the costs and efforts.

An analysis based on official data from Romanian National Institute for Statistics revealed that only 9 cities out of 41 major cities are accomplishing the requirement of green areas more than $20 \mathrm{sq} \mathrm{m} /$ inhabitant (Bucharest, Bacau, Oradea, Botosani, Calarasi, Cluj Napoca, Craiova, Miercurea Ciuc and Suceava). Green areas (ha) refers to the area of green spaces as parks, public gardens or public squares, sports fields and facilities within the localities. There are not included greenhouses, nurseries, vegetable gardens, cemeteries, and farmland and lakes area. Official data from 2013 have not yet been published but it is unlikely that in such a short time any city have reached the desired standard of $26 \mathrm{sq} \mathrm{m} /$ inhabitant.

Most of all, the urban developments during the last 10 years reduced the green areas around cities, caused by urban sprawl, and within the city caused by competitive commercial developments. The result, especially for the major urban areas, is a low surface of green area per inhabitant of about $20 \mathrm{sq} \mathrm{m}$.

The second aspect which may be related to urban green structure is represented by the National Strategy for Sustainable Development, implemented in 2008, which is mentioning for Horizon 2013 to establish and implement action plans in order to achieve green/yellow belts (green spaces and farmland) around cities $1^{\text {st }}$ and $2^{\text {nd }}$ rank and also to increase green spaces within the built surfaces with $10 \%$ in order to achieve a minimum of $15 \mathrm{sq} \mathrm{m} /$ inhabitant.

Provisions established in the Strategy in relation to green areas in cities (15 sq m/inhabitant until 2013) are not complying with the provisions of the legislation mentioned above (min. $26 \mathrm{sq} \mathrm{m} /$ inhabitant at the end of 2013). The Strategy however establishes the first roots of green structure defined by green/yellow belts around cities.

For Horizon 2020 the Strategy [2] is mentioning the achieving effective green-yellow belts around cities $1^{\text {st }}$ rank; achieving an indicator of green space per inhabitant of $26 \mathrm{sq} \mathrm{m}$ for cities $1^{\text {st }}$ and $2^{\text {nd }}$ rank.

For Horizon 2030 the Strategy [2] is highlighting the importance of making green-yellow belts around cities $2^{\text {nd }}$ rank, achieving an indicator of green space of $35 \mathrm{sq} \mathrm{m} /$ capita for cities $1^{\text {st }}$ and $2^{\text {nd }}$ rank.

Rank is defined by Law 351/2001 as: Rank 0 - Bucharest, Rank 1 - cities of national importance, with potential influence at European level, and Rank 2 - 
municipalities with intercounty, county importance or steady role in network settlements.

The third aspect in relation with green areas is related to the NSRCC [3] which includes in the specific objectives "Increasing green spaces in urban and sub-urban areas".

The fourth aspect is related to LAPE (Local Action Plans for Environment) established at county level which include also an increase of green areas at counties' level.

None of these documents are really supported by actions at local level.

\subsection{Short review of planning system in Romania}

The planning system in Romania is decentralized to the local government level and contains statutory plans and non-statutory plans. Both types provide projects organized per sectors, social, economic, environment, etc. The statutory plan for cities is the General Urban Plan, development plan type combined with zoning regulation, which is valid for 10 years. The counties have the County Land Use Plan. Both plans have a methodological framework and an approval procedure. Cities and counties have also non-statutory plans, development strategies, designed for 15-20 years, and cover sectors that support the community development.

In the past years, a new planning instrument - the Integrated Urban Development Plan (IUDP) - was used for Growth Poles (GPs), Urban Development Poles (UDPs), and Urban Centers (UCs), as required to apply for funding available through Axis 1 for urban development under the 2007-2013 Regional Operational Programme. This plan includes the same chapters as the City Strategy, but it also goes beyond the city's administrative boundaries, typically covering the metropolitan areas (defined, according to the legislation, as the 30 kilometer buffer around the main urban center). IUDPs include a list of projects, based on an estimation of the pre-determined ROP allocation.

There is a large debate at the urban policy level to increase, at the urban level, both pedestrian areas and green areas as forms for increasing the cities' attractiveness, by, for instance, developing areas for recreation, sports, and activities for various user groups, and reducing the air pollution.

At the level of planning instruments, the general urban plan and zoning regulations, face difficulties in implementing the green policy. The urban plans used by local governments present the existing situation regarding the surfaces of public parks and gardens, but without vegetation types. The private gardens are not registered.

At the same time there is no methodological framework in designing and implementing actions and measures in the green structure of the urban areas. The "green cadastre" process implemented in several Romanian cities is not a decision making tool in urban development, and do not provide inputs for proactive measures in both conservation and development of the green areas.

Consequently, the bottlenecks of the current management of the green cadastre in Romania are: 
1. The manual effort needed to collect and maintain the required information is too big compared to the perceived usefulness of the resulting green cadastre.

2. The cities are not adhering to the required minimum green area per inhabitant.

\subsection{Analysis of green areas situation in the Growth Poles}

Growth Poles (GPs) are represented by seven large urban centers (Iaşi, Constanţa, Ploieşti, Craiova, Timişoara, Cluj-Napoca şi Braşov) and their influence areas. Even if Bucharest is not considered as GP, its situation was also analysed.

The evolution of green areas between 1993 and 2012 (approx 20 years) in the 7 GPs and Bucharest is presented in the figure 3.

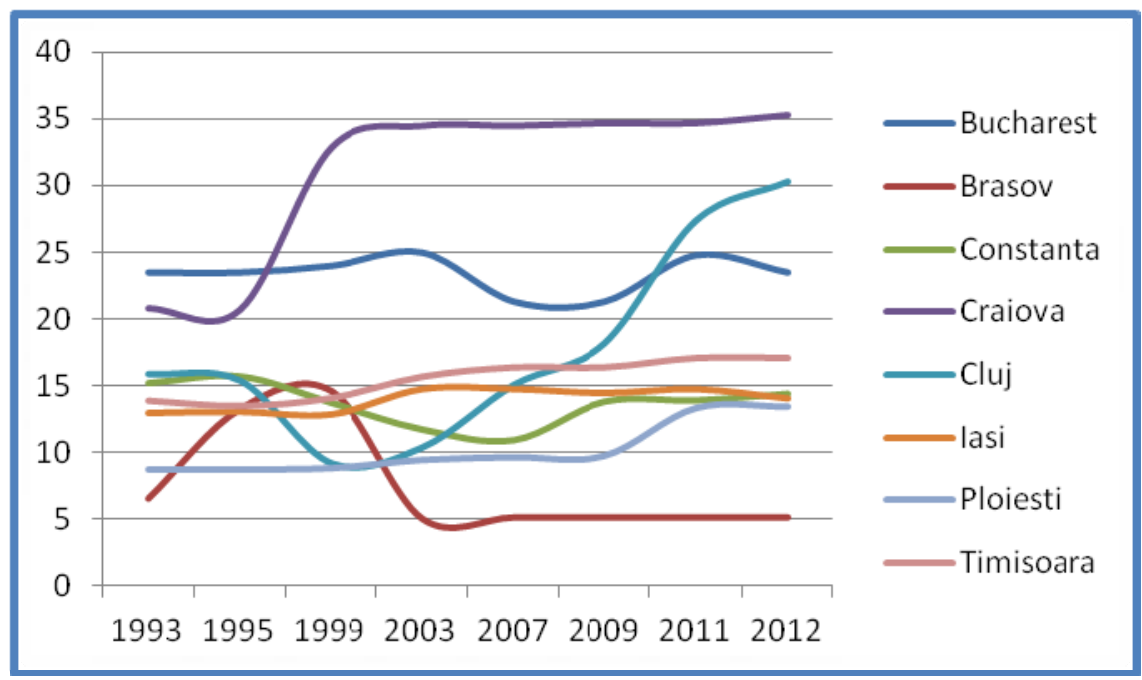

Figure 3: Evolution of green areas in the 7 GPs and Bucharest municipality 1993-2012. Calculations were made by team members, based on official data issued by National Institute of Statistics, TEMPO database.

According to figure 3, in the past years only Craiova and Cluj invested in green areas creation. The weakest situation was discovered in Brasov which experienced an exponential decrease of green areas/inhabitant.

\subsubsection{Bucharest brief case study}

In 1989, Bucharest (228 kmp) had 3,470 hectares of green spaces. Official statistics are revealing green spaces of 4,839 ha, starting from 1996 until 2009, indicating a decrease to 4,506 ha green areas from 2010 until 2012. However, various papers such as BEPA [14] and BS 2035 [15] are indicating drastic decrease of green spaces by about $50 \%$, from 3,471 ha in 1989 to 1,708 ha in 
2004. According to Chiriac et al. [16], in 2006 the green structure was formed predominantly by green spaces within the residential areas $(56.0 \%)$ and street alignments $(24.5 \%)$, parks and gardens accounting for only $19.5 \%$.

Reduction of green areas in Bucharest was due to several causes:

A. Bucharest municipality has no land policy. The City Hall was not ready to handle demand of lands for buildings construction, and addressed this demand with planted public lands, free of buildings.

B. Retrocession of green spaces were allowed from public space to the private one for new buildings. The Land Law no. 18/1991 allowed restitution of green spaces. Given the increasing demand for housing and the lack of space for construction, these lands represented a valuable stake, particularly for the developers. Thus a conflict arose between the population who was not able to benefit anymore from public green spaces for leisure and real estate companies willing to expand their business by monopolizing the land suitable for buildings construction (housing, offices, banks etc.).

C. Abusive occupation of parks areas for restaurants development. Another cause which led to the reduction of urban green spaces was due largely to commercial spaces development on the green areas. After 1990 there were such spaces developed in parks, in certain areas, based on agreements between the holders of these units and local authorities, with the obligation to respect the green spaces. In most of the cases these were not respected and the new units have expanded without permits. Therefore, concrete surfaces increased and illegal construction has emerged, which significantly decreased green spaces.

Nowadays, Bucharest can be proud that is has 23 square meters of green space per inhabitant - more than Paris and Madrid. For the measurements Bucharest municipality has launched in 2011 the first Green Areas Inventory (green cadastre). Still, there is more to be done. The city still needs to increase green areas in order to meet the minimum 26 square meter asked by legislation.

At the same time local urban planning documents does not include green structure provisions, just proposals for green areas regulations or projects for green areas rehabilitations (e.g. IUDP Creanga in the 2nd district includes creation of a park with 1.96 ha on the area which was formerly occupied with unauthorized waste). These initiatives are more than welcome but Bucharest still needs a strategic view for the green structure creation: green areas need to be designed and created in order to create a coherent spatial green network that should link the open spaces, public parks, public or private gardens, leisure areas, sports grounds green street alignments etc.

BS [15] identifies as the most important problems at Bucharest level in relation to green areas:

- lack of a coherent representative public spaces and green spaces;

- lack of quantitative and qualitative public spaces and green spaces;

- degradation or overuse of existing green spaces and unequal distribution/accessibility across the city.

The strategy is aiming to develop the green structure but the action plan includes insufficient developed measures:

- reservation of spaces - for planted area creation; 
- $\quad$ protection areas for isolating noise pollution sources (traffic, industry) from residential areas.

Even if a map is attached, few details are provided in relation to location, surface, type of vegetation etc.

\subsubsection{Cluj brief case study}

In 2014 Cluj (304,520 inhabitants) is the third largest city in Romania, following Bucharest (1,908,669 inhabitants) and Iasi (332,271).

The IUDP developed in 2009 does not include in the action plan any project related to green areas. Green structure/infrastructure is not even mentioned.

The General Urban Plan [17], developed in 2013 described the green areas situation and proposed 4 objectives related to green areas.

The municipality developed in 2014 the strategy [18] which included a robust analysis of green areas. This emphasized a visible deficit of green areas in the eastern districts and also a strong fragmentation of green areas in the districts considered to be rich in green spaces. At the same time green compact spaces with large area are very few in the analyzed urban context. The Strategy emphasized that just reporting green areas to the population is not enough, is extremely important to consider the balanced distribution of green spaces, their interconnection and especially the availability and connection levels of inhabitants on these areas.

\section{Conclusions, proposals and recommendations at local level}

The paper is highlighting the need to increase green spaces in major cities to meet Romanian legislation in force. Since it is already a European term, green structure is necessary to be introduced in Romania. At the same time, the 2 brief case studies presented are emphasizing either the need for a green structure plan in the urban planning framework, either introduction of new chapters related to green structure within General Urban Plans, Local Strategies, or IUDPs.

Trier [19] highlighted that a municipality may be interested in a green structure plan for several reasons:

1. To map current status of green areas and their changes over time.

2. To maintain biological diversity. Different species or groups of species use different varieties of green structure as corridors.

3. Green structures are being used for recreation.

4. Vegetation converts carbon dioxide to oxygen, reduces noise, and has aesthetical value. Vegetation also binds water, reducing the prospect of floods after heavy rainfall.

5. If accurate, the green structure map can be used in overlays.

Since green structure is not yet included in the planning documentations, we are proposing to introduce it according to the following scheme:

Green structure should be included both in the statutory or non-statutory documents at municipal level: General Urban Plan or Integrated Urban Development Plan/Local Strategy (accommodating projects related to green structure) or may be considered a separate plan, namely Green Structure Plan. 


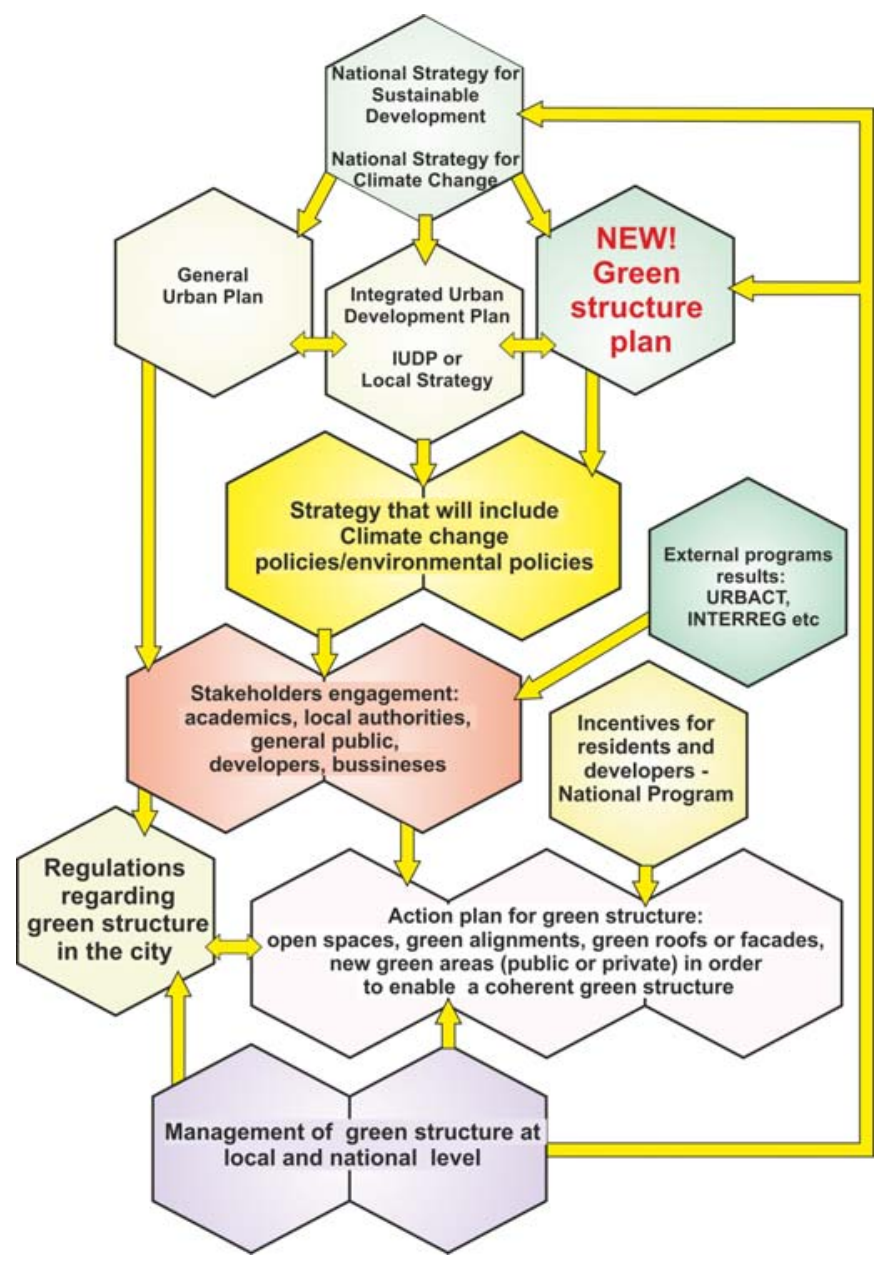

Figure 4: Proposal for introducing green structure in urban planning documentation in Romania.

The proposed scheme above is emphasizing the role of local stakeholders since they may be strongly involved in defining and implementing projects in the action plan at private level: e.g. greening the roofs, greening the private yards etc. Stakeholder's engagement should also build on experience brought by external programs with the bottom-up approach used by URBACT Local Support Groups (ULSG). Since 2007 URBACT II has involved around 500 cities in approximately 60 thematic exchange and learning networks. Each city that takes part in an URBACT II network has set up a broad multi-stakeholder local support group, which develops a local action plan.

In many existing urban areas will not be feasible to create new large green areas. Nevertheless the green structure plan or the Local Strategy will establish if conventional green areas will be created or will creatively make use of roofs or 
facades greening, street alignment (with tree planting) etc. According to Liu and Baskaran [20] "greening the roofs could reduce the temperature of the roof membrane significantly in the summer".

Public incentives should be used in order to convince developers or citizens to improve urban structure by greening their yards and/or roofs/facades. National Incentives Program may support to achieve energy savings, promote aesthetic qualities of neighborhoods, and also create better microclimate conditions to prepare for future rising temperatures associated with climate change.

\section{References}

[1] Law no. 24, 2007, Romanian Parliament, Romania’s Official Monitor 764, 2009.

[2] National Strategy for Sustainable Development of Romania - Horizon 2013-2020-2030, Ministry of the Environment and Forests, 2008 http://www.mmediu.ro/dezvoltare_durabila/strategia_nationala.htm.

[3] National Strategy of Romania regarding Climatic Changes 2013-2020, Ministry of the Environment and Forests, 2012 http:/www.mmediu.ro/beta/ wp-content/uploads/2012/10/2012-10-05-Strategia_NR-SC.pdf.

[4] Intergovernmental Panel on Climate Change, 2007.

[5] Kazmierczak, A. \& Carter, J., Adaptation to climate change using green and blue infrastructure. A database of case studies. University of Manchester, GRaBS project, 2010.

[6] Parlow, E., Radiation and Heat Fluxes of an Urban Surface. Proc. of the $3^{\text {rd }}$ International Symposium, Remote Sensing of Urban Areas, 11-13 June 2002, Istanbul, Turkey, Vol. I, pp. 259-266, 2002.

[7] Parlow, E., Remotely-sensed heat fluxes of urban areas. Biometeorology and urban climatology at the turn of the millennium. WMO Tech. Doc. vol. 1026, World Meteorological Organization: Geneva, Switzerland, pp. 523528, 1999.

[8] Parlow, E., The urban heat budget derived from satellite data. Geographica Helvetica, 2, pp. 99-111, 2003.

[9] Parlow, E., Urban Climate. Urban Ecology - Patterns, Processes, and Applications, ed. Niemelä, J., Oxford University Press, p. 392, 2011.

[10] Urban Climate Study of Bucharest (UCS), Romania, 2013, http://urbanclimate.utcb.ro/.

[11] Ghorbani, A., Mossivand, A. M. \& Ouri, A. E., Utility of the Normalized Difference Vegetation Index (NDVI) for land/canopy cover mapping in Khalkhal County (Iran). Annals of Biological Research, 3(12), pp. 54945503, 2012.

[12] Qi, J., Chehbouni, A., Huete, A. R., Kerr, Y. H. \& Sorooshian, S., A Modified Soil Adjusted Vegetation Index. Remote Sensing of the Environment, 48, pp. 119-126, 1994.

[13] Agone, V. \& Bhamare, S. M., Change detection of vegetation cover using Remote Sensing and GIS, Journal of Research and Development, 2(4), 2012. 
[14] Report on the state of the environment in Romania in the year 2005; Romanian Environmental Protection Agency, Bucharest, 2006, http:// www.anpm.ro/Mediu/raport_privind_starea_mediului_in_romania-15.

[15] Bucharest Strategy 2035, Strategy for integrated urban development of Bucharest and its area of influence, Bucharest City Hall, 2011, www.csb2035.ro.

[16] Chiriac, D., Humă, C., Stanciu, M., Green areas - problem of present urbanization. Life Quality, XX(3-4), pp. 249-270, 2009.

[17] The General Urban Plan Cluj, Bucharest City Hall, 2013.

[18] "Green Cluj" Environmental Policy, Strategically Planning of the ClujNapoca Municipality, 2014-2020, 2013, http://cmpg.ro/wp-content/ uploads/2014/02/STRATEGIE-MEDIU-CLUJ-2014-2020_FINAL.pdf.

[19] Trier, Ø. D., Urban green structure. State of the art of classification methodology, Norvegian Computing Center, 2011.

[20] Liu, K. \& Baskaran, B., Thermal performance of green roofs through field evaluation, National Research Council Canada, Institute for Research in Construction, Report no. NRCC-46412, 2003. 